\title{
Uterine ruptures during labor: a study of 26 cases at Nabil Choucair Medical Center, in the suburbs of Dakar
}

\author{
Omar Gassama*, Mouhamadou Mansour Niang, Abdoul Aziz Diouf, Youssoupha Toure, \\ Aissatou Mbodji, Marie Edouard Faye Dieme, Philippe Marc Moreira, Jean Charles Moreau
}

Department of Obstetrics and Gynecology Clinic, Teaching Hospital Aristide, Le Dantec, Cheikh Anta Diop University, Dakar, Senegal

Received: 11 March 2017

Accepted: 07 April 2017

*Correspondence:

Dr. Omar Gassama,

E-mail: ogasse79@yahoo.fr

Copyright: () the author(s), publisher and licensee Medip Academy. This is an open-access article distributed under the terms of the Creative Commons Attribution Non-Commercial License, which permits unrestricted non-commercial use, distribution, and reproduction in any medium, provided the original work is properly cited.

\begin{abstract}
Background: This study aims to clarify the epidemiological profile of patients and describe the diagnostic, therapeutic and prognostic aspects of uterine ruptures at Nabil Choucair Health Center, in the suburbs of Dakar.

Methods: This was a retrospective and prospective, descriptive and analytical study conducted over a period of 112 months, from July 31, 2005 and March 31, 2015; it concerned all diagnosed cases with uterine rupture, managed at Nabil Health Center Choucair Dakar. Data were collected from antenatal notebooks, delivery records, surgical reports and anesthetic records. The following parameters were studied: socio-demographic characteristics (frequency, chracteristics of patient), the course of pregnancy, diagnostic, prognostic, and therapeutic aspects. Data analysis was performed using SPSS software (version 11.0).

Results: During the study period, we recorded 26 uterine ruptures from a total of 34,097 deliveries, that is a frequency of 8 out of 10,000 births. The epidemiological profile of the patients was that of a 30-year old woman, on average, few previous deliveries with an average parity of 3 , who received on average 3 antenatal and evacuated in $50 \%$ of cases. Uterine rupture occurred in 17 patients on a new uterus $(65,4 \%)$ and in 9 patients on a scarred uterus (34.6\%). Two patients (7\%) were in hemorrhagic shock. A laparotomy aimed at specifying the place of rupture and making the treatment was performed in all patients. It was 18 uterine segmento-corporeal ruptures (69.2\%), 5 segmental ruptures $(19.2 \%)$ and 2 corporeal ruptures $(7.6 \%)$. We recorded 9 uterine ruptures with living fetus $(38.5 \%)$. Twenty-three patients $(88.5 \%)$ underwent conservative suture against only 3 hemostasis hysterectomy (11.5\%). The postoperative courses were uneventful in $57.7 \%$ of cases. Eleven patients (42.3\%) had anemia and we recorded maternal deaths, which is a maternal mortality of $3.84 \%$.

Conclusions: Uterine rupture is a serious complication that is still responsible for significant maternal and fetal mortality. Prevention is based on careful monitoring of pregnancy and delivery.
\end{abstract}

Keywords: Conservative suture, Hemostasis hysterectomy, Uterine rupture

\section{INTRODUCTION}

Uterine ruptures are complete or incomplete discontinuities in the lining of the pregnant uterus, due to the existence of a weakening factor and/or excessive pressure on this lining. Most of the time, uterine ruptures happen during labor. ${ }^{1-3}$ In western countries (Europe, North-America), thanks to controlled main risk factors, major deteriorations on safe uterus are exceptional. ${ }^{3-6}$ Unlike western countries, developing countries, especially sub-Saharan African countries, experience 
frequent cases of uterine ruptures which constitute an extremely serious obstetrical complication. Uterine ruptures happen more frequently to a healthy uterus than to a damaged one and its main decisive factors include undiscovered dystocia and great multiparity. ${ }^{7-10}$

This study was conducted in Nabil Choucair Health Center, located in the suburbs of Dakar. Its main objectives were to determine patients' epidemiological profile but also to describe diagnostic, therapeutic and prognostic features of uterine ruptures.

\section{METHODS}

This is a retrospective, prospective, descriptive and analytical study conducted over a 112 month-period from July $31^{\text {st }}$ to March $31^{\text {st }}, 2015$; it focused on all the cases of uterine ruptures diagnosed and treated at Nabil Choucair Health Center in Dakar. Data were collected from prenatal consultation records, birth records, surgical reports and anesthesia records. The following parameters were considered: socio-demographic features, the course of pregnancy, the clinal picture during admission into the health center, as well as diagnostic, etiology, prognostic and therapeutic aspects. Data analysis was performed using SPSS software (version 11.0).

\section{RESULTS}

\section{Frequency}

Throughout the study period, we recorded 26 uterine ruptures out of 34,097 deliveries, representing a frequency of 8 out of 10,000 deliveries.

\section{Characteristics of patients}

Patients were between 19 and 43 years old with an average of 30 years old. The most represented age range was 25-35 (Table 1).

Table 1: Distribution of patients according to their age $(\mathrm{N}=26)$.

\begin{tabular}{|lll|}
\hline Age range (years) & Number & Frequency $(\%)$ \\
\hline $19-24$ & & 19.2 \\
\hline $25-30$ & 12 & 45 \\
\hline $31-36$ & 6 & 23.1 \\
\hline $37-42$ & 3 & 11.6 \\
\hline 43 and above & 1 & 3.8 \\
\hline Total & 26 & 100 \\
\hline
\end{tabular}

Parity ranged between 1 and 8 with an average of 3 . A total of twelve patients $(46.2 \%)$, underwent more than four prenatal consultations. However, 5 among our patients $(19.2 \%)$ did not undergo any prenatal consultation. Nine among our patients (34.6\%) previously underwent a caesarean section. Among these cases, there were 7 single-scar uterus $(26.9 \%)$ and 2 two-scar uterus
(7.7\%). Half of the patients were evacuated from peripheral health structures.

\section{Clinal picture during admission into the health center}

Cases of metrorraghia were reported among all patients with 2 cases of hemorraghic shock (7\%). On the admission into the health center, the foetus was turned towards the abdomen in $42.3 \%$ of cases. The mean duration of the pregancy was 37 weeks of amenorrhea (WA).

\section{Etiology}

The different etiology was (Table 2).

Table 2: Distribution of patients basing on the etiology of the uterine rupture $(\mathrm{N}=26)$.

\begin{tabular}{|lll|}
\hline Etiologies & Number & Frequency (\%) \\
\hline $\begin{array}{l}\text { Foeto-pelvic } \\
\text { disproportion }\end{array}$ & 13 & 50 \\
\hline $\begin{array}{l}\text { Scarred uterus } \\
\text { Abdominal pressures }\end{array}$ & 9 & 34.6 \\
\hline $\begin{array}{l}\text { Abusive use of } \\
\text { oxytocic }\end{array}$ & 2 & 7.7 \\
\hline Total & 26 & 7.7 \\
\hline
\end{tabular}

\section{Therapeutic cares}

All patients were subject to an initial resuscitation. Laparotomy was performed for all patients. It was used in order to draw up an average of 2 litres of hemoperitoneum and to precisely find out the location of uterine rupture which was segmental-coporeal among 18 patients $(69.2 \%)$, segmental among 5 patients (19.2) and corporeal among 2 patients $(7.6 \%)$.

The scope of the rupture was between 5 and $16 \mathrm{~cm}$ with an average of $7 \mathrm{~cm}$. The foetus was alive among 9 patients $(38.5 \%)$. Twenty-three (23) conservative sutures $(88.5 \%)$ and 3 hemostasis hysterectomies $(11.5 \%)$ were performed.

\section{Prognostic aspects}

Surgical outcomes were simple among 15 patients (57.7\% of cases).

Eleven patients (42.3\%) showed anaemia and we registered one maternal death, which represents a specific lethality of $3.8 \%$.

The deceased mother was a multiparous woman whose pregnancy was complicated by shoulder dystopia with an undiscovered uterine rupture, diagnosed 24 hours after delivery. As for the perinatal prognosis, we registered a total of 17 intrapartum deaths (61.5\% of cases). 


\section{DISCUSSION}

\section{Frequency}

The frequency of uterine ruptures found in our study $(0.08 \%)$ is below the rates reported in other African studies. Indeed, Privat reported a frequency of $2.26 \%$ in Bouaké which was similar to the one observed by Akotionga in Ouagadougou's Hospital Center. ${ }^{9,11}$ This difference is supposedly due to the fact that these studies were conducted in reference health centers dedicated for the treatment of serious cases whereas our study structure was adjacent to surgical maternities capable of coping with uterine ruptures. However, in advanced countries, uterine rupture has become an exception and almost only happens to cases involving scarred uterus. In the United States, incidences vary from $1 / 1000$ to $1 / 1500$ pregnancies and from $1 / 1000$ to $1 / 2000$ pregnancies in France. ${ }^{6,12}$ These lower rates are underlied by better access to healthcare and by higher-quality technical platforms which are better suited for the treatment of uterine ruptures.

\section{Characteristics of patients}

The epidemiological profile was that of a 30 years old low-parity women with a mean parity of 3 , who has undergone an average of 3 prenatal consultations and been evacuated in $50 \%$ of cases.

Many authors recognize that age is a risk factor of uterine ruptures. In our study, the most representative age range was 25 to 35 years. The same observation was made by Akotionga in the Maternity of Yalgado Hospital Center in Ouagadougou, Kouakou in the University-affiliated Hospital of Bouaké and Dolo in Gabriel Touré Maternity in Bamako. ${ }^{9,10,13}$ This age range is also similar to the one found in developped countries like France where the age of the first pregnancy is about 30 years.

In our countries, uterine rupture especially happens to uterines that are fragilised by multiparity, most oftenly in a context of feoto-pelvic disproportion or dystocic presentations. ${ }^{1,2,8,10,14}$ The inappropriate use of oxytocic also plays a significant role although it is difficult to measure since previous treatments are rarely mentionned in evacuation records. ${ }^{8,10}$

The frequency of ruptures increseas according to parity and the drop in the inter-pregnancy interval, through histological changes of the uterus especially in the myometer that tends to become fibrous and less vital. This is corroborated by the fact that sub-saharan African countries, that register the highest rates of uterine ruptures in the world, have the most pejorative reproduction features: a high birth rate (3 or four times higher than in advanced countries), an early and longlasting fecundity, an average inter-pregnancy interval below 18 months, and an average number of children above 5.1,12

\section{Etiologic factors}

Mechanical dystocia, more precisely foeto-pelvic disproportion, was the most common etiologic factor in our study (50\% of cases). In the study conducted by Rajaonarison. ${ }^{15}$ In Madagascar, uterine rupture was caused by a mechanical dystocia among 13 of the 31 patients considered in the study $(41.9 \%)$. We agree with him that the predominance of mechanical causes is a characteristic shared by developped countries due to poor compliance with follow-up appointments among patients, the low detection rates of these abnormalities by health care providers and problems of access to surgery centers related to road infrastructure. ${ }^{1,8,10}$ The $3^{\text {rd }}$ quarter perinatal consultation, especially during the $8^{\text {th }}$ month, should indeed enable the detection of mechanical abnormalities that may hinder the delivery and, as a result, allow for the development of delivery methods. ${ }^{16,17}$

Ohter etiological factors such as scarred uterus (34.6\%), abdominal pressures $(7.7 \%)$ and the abusive use of uterotonics $(7.7 \%)$ were observed in our study. The same results were found in different African studies. ${ }^{1,8-10}$ In Rajaonarison's study, it was proved that the use of prostagladin for cervical ripening to induce labor increases 7.2 times the risk of uterine rupture than without this drug. ${ }^{15}$ As for scarred uterus, the frequency found in our study is slightly above those found by Gueye in 1992 and 1996 in Senegal, which was 10.4\% and 18\% respectively. This gradual increase of the rate of scarred uterus in the causes of uterine rupture is partly underlied by a higher caesarean section rate in Senegal, which increased from $1.1 \%$ in 2000 to $4.4 \%$ in $2014 .^{18}$

\section{Therapeutic care}

Uterine rupture is a major surgical emergency treated through an initial resuscitation (vascular filling, blood transfusion) combined with an urgent laparotomy. We performed 23 conservative stiches $(88.5 \%)$ and 3 hemostasis hysterectomies $(11.5 \%)$, contrary to the results found by Gueye who reported far higher hemostasis hysterectomy rates of $96.7 \%$ and $78 \%$ in 1992 and 1996 respectively. ${ }^{10}$ This shows the important progress made in terms of uterine rupture treatment in Senegal, mainly through an earlier diagnosis and treatment of cases.

\section{Prognostic aspects}

The maternal mortality rate found in our study $(3.5 \%)$ is well below those reported by Gueye in 1992 and 1996 in Senegal which were $28.3 \%$ and $12 \%$ respectively. ${ }^{10}$ So we notice a substantial drop in maternel deaths following uterine rupture due probably to an increased access to surgery structures, to an improvement of the technical platform and to better trained health workers capable of handling these cases. However, the perinatal prognosis remains gloomy. Indeed, our perinatal mortality rate remains high, even if it is well below those reported by 
Gueye. ${ }^{10}$ It is similar to those reported in developping countries, ranging from 45 to $90 \% .^{9,10,12,19}$ The time lag between the diagnosis of the uterine rupture and the performance of laparotomy which is still very long, along with the shortage of health workers and suitable structures in the area of perinatalogy could explain the heavy price payed by the foetus.

\section{CONCLUSION}

Uterine rupture remains a frequent pathology in our country. In spite of the efforts made in terms of diagnosis and treatment, the perinatal prognosis remains poor. The improvement of the technical platform of our health structures, the enhancement of the quality of perinatal consultation, the identification and reporting of riskpregnancies could reduce its frequency and improve its prognosis.

Funding: No funding sources Conflict of interest: None declared

Ethical approval: Not required

\section{REFERENCES}

1. Koné M, Diarra S. Uterine rupture during pregnancy. EMC. Obstetrics.. 2008;5-080-A-10.

2. Merger R, Levy J, Melchior. Precis of Obstetrics. 6th ed. Masson, Paris, 1995;348-53.

3. Boulanger JC. Uterus scarring and childbirth. In: National College of Gynecologists and Obstetricians. Updates in gynecology and obstetrics. Diffusion Vigot. Paris. 1984;203-35.

4. Cassignol C, Rudigoz RC. Pregnancy and uterus cicatriciel.Encycl Med Chir Obstét. 2003;(1)5-016D-20.

5. Maria B, Cornet MC. Uterine rupture during pregnancy. In: Encycl Med Chir (Ed.) Obstetrics. 05080-A10 Paris. 1981;6.

6. Eden RD, Parker RT, Gall SA, Bretones S. Rupture of the pregnent uterus: a 53 years review. Obstet Gynecol. 1986;68:671-4.

7. Cazenave JC, Breda JY, Belier L, Nicoloso E, Courbil LJ. Uterine ruptures in Black Africa. A problem still topical. Results of a retrospective survey of 453 cases in six inter-tropical Black Africa centers. Surgery. 1988;114: 76-82.

8. Cissé CT, Faye EO, De Bernis 1, Diadhiou F. Uterine rupture in Senegal: Epidemiology and quality of care. Med trop. 2002:62:619-22.
9. Akotionga M, Lankoande J, Gue MJ, Kone B. Uterine rupture in maternity at $\mathrm{CHN}-\mathrm{YO}$ Epidemiological and clinical aspects. Medicine of Black Africa. 1998;45:(8/9).

10. Gueye SM, Moreau JC, Moreira PM. And Coll. Uterine rupture in Senegal: results of two surveys carried out in 1992 and 1996. J Gynecol Obstet Biol Reprod. 2001;30:700-5.

11. Kouakou P. Uterine ruptures: epidemiological aspects and materno-fetal prognosis at the maternity hospital of Bouake University Hospital rev. Cams series. 2007;5:87-91.

12. Bretones S, Cousin C, GualandI M, Meiller G Uterine rupture: about a case of spontaneous rupture at $30 \mathrm{SA}$ in a primary patient. J Gynecol Obstet Biol Reprod. 1997;26:324-7.

13. Dolo A, Keïta B, Diabate FS, Maïga B. Uterine ruptures during labor: about 21 cases at 'G Point National Hospital, Bamako. Medicine of Black Africa. 1991;38:2.

14. Abarikoto HF. Uterine ruptures during labor, observed at the CHUA / GOB Antananarivo Madagascar Revue d'Anesthésie-Réanimation et de Medicine d'Urgence. 2010;2(1):5-7.

15. Rajaonarison JJC. Uterine rupture during labor: etiologic factors and materno-fetal prognosis. Rev. anesth.-Réanim. med. Urgence. 2014; 6(1):8-12.

16. Randriambelomanana JA, Botolahy ZA, Harimiandatsoa T, Heriniaina SA, Rakotoarijaona A, Andrianampanalinarivo HR. Uterine rupture: Study of 57 cases seen at the University Hospital Center of Toamasina Madagascar. RevAnesth-Réanim Méd Urg. 2010;2(3):4-6.

17. El Mansouri A. Rupture uterine: 50 cas. Rev Fr Gynecol. 1995;90:208-14.

18. Ministry of Health and Social Action of Senegal. Assessment of Neonatal Emergency Neonatal Needs (SONU) Needs in Senegal. 2012-2013:77.

19. AliIhonou E, et al Uterine ruptures. Favorable factors and prophylactic measures. Dakar Med 1983;28:5539.

Cite this article as: Gassama $\mathrm{O}$, Niang MM, Diouf AZ, Toure Y, Mbodji A, Dieme MEF, et al. Uterine ruptures during labor: a study of 26 cases at Nabil Choucair Medical Center, in the suburbs of Dakar. Int J Reprod Contracept Obstet Gynecol 2017;6: 2154-7. 